\title{
3 Research Square \\ One-Step Direct Oxidation of Alkoxy to Ketone for Evaporable Fullerene-Fused Ketone as Efficient Electron-Transport Materials
}

Hao-Sheng Lin

The University of Tokyo

Yue Ma

Northeast Normal University

Rong Xiang

The University of Tokyo

Sergei Manzhos

Institut National de la Recherche Scientifique

II Jeon

The University of Tokyo

Shigeo Maruyama

The University of Tokyo https://orcid.org/0000-0003-3694-3070

Yutaka Matsuo ( $\nabla$ matsuo@chem.material.nagoya-u.ac.jp )

Nagoya University https://orcid.org/0000-0001-9084-9670

\section{Article}

Keywords: Ketones, substantially curbed, alcohols, favorable energy barrier, high electron-transport mobility

Posted Date: January 7th, 2021

DOl: https://doi.org/10.21203/rs.3.rs-131562/v1

License: (1) (1) This work is licensed under a Creative Commons Attribution 4.0 International License. Read Full License

Version of Record: A version of this preprint was published at Communications Chemistry on May 21st, 2021. See the published version at https://doi.org/10.1038/s42004-021-00511-4. 


\section{Abstract}

Ketones, one of widely applied moieties in designing electrical and medical materials, commonly converted from the alcohols through the oxidation reactions. However, when alcohols are protected/functionalized, the direct oxidation strategies are substantially curbed. Here we show a highly efficient copper bromide promoted one-step direct oxidation of alkoxy to ketone with the aid of a fullerene pendant. Mechanistic studies unveil that fullerene can serve as an electron poor proceeding the one-step oxidation of alkoxy group to ketone. In the absence of fullerene pendant, the unreachable activation energy threshold hampers the direct oxidation of alkoxy group. In the presence of fullerene pendant, copper bromide oxidized fullerene radical cation can activate neighboring $\mathrm{C}-\mathrm{H}$ bond of alkoxy moieties, allowing a favorable energy barrier for initiating the direct oxidation of alkoxy group. Produced fullerenefused ketone indicates high thermal stability, affording the pin-hole free and amorphous electrontransport layer with high electron-transport mobility.

\section{Introduction}

Oxidation reactions, such as the direct oxidation of alcohols to aldehydes or ketones, are among the most critical and fundamental transformations in organic synthesis. ${ }^{1}$ However, the oxidation methods are limited when alcohols are protected/functionalized with an alkyl group to form the alkoxy structure, ${ }^{2}$ which is mainly attributed to high activation energy barrier for directly converting the alkoxy group to ketone structure. ${ }^{3}$ Consequently, the one-step direct oxidation of alkoxy to ketone has yet to be presented. Fullerene, a well-known intrinsically electron-deficient molecule, is prone to accept electrons affording the reduced fullerene anion species for versatile functionalizations. ${ }^{4,5}$ With our interest in exploring the classical organic chemistry reaction under assistance of fullerene, and also inspired by the recent studies on fullerene radical cation $\left(\mathrm{C}_{60}{ }^{\circ+}\right)$ mediated reaction, ${ }^{6,7}$ we conceived that $\mathrm{C}_{60}{ }^{\cdot+}$ should be feasible for the one-step oxidation of alkoxy group to ketone through the electron transfer activation. Herein, we report a copper (II) bromide promoted one-step direct oxidation of alkoxy to ketones with the aid of an oxidizable fullerene pendant (Fig. 1). Distinct from the unfavourable energy barrier in direct oxidation of alkoxy group to ketone, fullerene pendant serves as an electron pool for facilitating the electron transfer from the alkoxy structure to oxidant. Mechanistic studies indicate that the fullerene assisted one-step oxidation involves two critical steps: 1 ) electron transfer from $\mathrm{C}_{60}$ to $\mathrm{Cu}\left[\mathrm{III}\right.$ affords $\mathrm{C}_{60}{ }^{\circ}$, and 2) the generated $\mathrm{C}_{60}{ }^{*+}$ attracts electron density from the neighbouring $\mathrm{C}-\mathrm{H}$ bond, contributing to the further electron transfer from the alkoxy structure to the fullerene cage. Meanwhile, obtained fullerene-fused ketones are fabricated to the electron-transport layers through thermally deposition, which provides the photovoltaic devices with uniformly pin-hole free electron-transport films. The reaction presented herein not only provides an understanding on one-step oxidation of alkoxy group to ketone, but also access the highquality electron-transport layers through thermally evaporation.

\section{Methods}


General procedures for the one-step oxidation reaction. For fullerene-fused ketones 2 , all reactions were performed by using $0.03 \mathrm{mmol}$ of $1,0.12 \mathrm{mmol}$ anhydrous $\mathrm{CuBr}_{2}$ (Sigma-Aldric) in $10.0 \mathrm{~mL}$ of anhydrous o-dichlorobenzene (o-DCB) under an argon atmosphere or open-air condition at $100{ }^{\circ} \mathrm{C}$ for 1.5 hours. After reaction was over, resulting mixture was directly filtered through a silica gel plug to remove insoluble salt, and then evaporated in vacuo to remove the excess solvent. Finally, the residue was further separated on a silica gel column with $\mathrm{CS}_{2}$ or $\mathrm{CS}_{2}$ /dichloromethane as eluents to afford products 2 .

${ }^{18} \mathrm{O}$ isotope-labeled experimental procedure. $3.0 \mathrm{mg}(3.6 \mu \mathrm{mol})$ of $1 \mathrm{a}$ and $1.5 \mu \mathrm{L}$ of $\mathrm{H}_{2}{ }^{18} \mathrm{O}(0.072 \mathrm{mmol}$, 20.0 equiv) were added to $3.0 \mathrm{~mL}$ of anhydrous $\mathrm{o}-\mathrm{DCB}$ solution in the presence of $\mathrm{CuBr}_{2}$ (3.2 $\mathrm{mg}, 14.4$ $\mu \mathrm{mol}, 4.0$ equiv). After being vigorously stirred at $100^{\circ} \mathrm{C}$ for $1.5 \mathrm{~h}$ with a tiny sealed tube, resulting mixture was directly filtered through a silica gel plug to remove insoluble materials. Finally, the filitrate was condensed in vacuo for the following HRMS measurement.

TEMPO experimental procedure. $3.0 \mathrm{mg}(3.6 \mu \mathrm{mol})$ of $1 \mathrm{a}, 3.2 \mathrm{mg}$ of $\mathrm{CuBr}_{2}(14.4 \mu \mathrm{mol}, 4.0$ equiv), and 2,2,6,6-tertramethyl-1-piperidinyloxyl (TEMPO) (2.3 mg, 4.0 equiv; $5.6 \mathrm{mg}, 10.0$ equiv) were added to 3.0 $\mathrm{mL}$ of anhydrous $\mathrm{o}$-DCB solution. After being vigorously stirred at $100^{\circ} \mathrm{C}$ for $1.5 \mathrm{~h}$ under the argon atmosphere, resulting mixture was directly filtered through a silica gel plug to remove insoluble materials. Finally, ca. $50 \mu \mathrm{L}$ of filitrate was directly loaded on HPLC to analyze results.

Measurement of trap-filling limit voltage $\left(V_{\mathrm{TFL}}\right)$ and trap density $\left(n_{\mathrm{t}}\right) . V_{\mathrm{TFL}}$ and $n_{\mathrm{t}}$ were evaluated based on space-charge-limited current (SCLC) using charge carrier only devices with a configuration of ITO/Fullerenes $(75 \mathrm{~nm}) / \mathrm{Au}(60 \mathrm{~nm})$. The $V_{\mathrm{TFL}}$ and $n_{\mathrm{t}}$ were calculated from the following equation: $V_{T F L}=\frac{n_{t} e d^{2}}{2 \varepsilon_{0} \varepsilon_{r}}$, where $e$ is electric charge $\left(1.602 \times 10^{-16} \mathrm{~V} \mathrm{~m}^{-1}\right),{ }_{0}$ is the vacuum permittivity $\left(8.85 \times 10^{-19} \mathrm{~V}\right.$ $\left.\mathrm{m}^{-1}\right), \mathrm{r}$ is the relative permittivity taken as 46.9 , and $d$ is the thickness of the fullerene layer. The thickness of the fullerene layer was measured by using cross-sectional scanning electron microscopy. The experimental dark current density was measured under an applied voltage swept from 0 to $-5 \mathrm{~V}$.

Measurement of electron mobility. The electron-transport layer only device with a configuration of ITO/Fullerenes $(30 \mathrm{~nm}) / \mathrm{Al}(80 \mathrm{~nm})$ was fabricated to evaluate the electron carrier mobility of synthesized fullerene-fused ketone. The mobility was determined by fitting the dark current to a model of a SCLC, which is described by the equation: $J_{S C L C}=\frac{9 \varepsilon_{0} \varepsilon_{r} \mu V^{2}}{8 L^{3}}$, where $J_{S C L C}$ is the current density, $\mu$ is the electron mobility, $e_{0}$ is the vacuum permittivity $\left(8.8510^{-19} \mathrm{~V} \mathrm{~m}^{-1}\right), e_{0}$ is the relative permittivity taken as $46.9, L$ is the thickness of the fullerene layer, and $V$ is the effective voltage. The thickness of the fullerene layer was measured by using cross-sectional SEM. The experimental dark current density was measured under an applied voltage swept from 0 to $-3 \mathrm{~V}$.

\section{Data availability}


The authors declare that the data supporting the findings of this study are available within the paper and its supplementary information files, or from the corresponding author upon reasonable request.

\section{Results}

Reaction optimization. Applied alkoxy substrate, indano[60]fullerene 1a, was synthesized according to our previously reported fullerene-cation-mediated synthetic strategy. ${ }^{8}$ The optimized reactions are summarized in Table, which includes the screening of the oxidants, reaction temperature, and reaction time. The optimized conditions successfully achieved [60]fullerene-fused ketone $2 \mathbf{a}$ was obtained in an isolated yield of $94 \%$, with 4.0 equiv. $\mathrm{CuBr}_{2}$ as oxidant in an ortho-dichlorobenzene (o-DCB) solution at $100{ }^{\circ} \mathrm{C}$ for $1.5 \mathrm{~h}$ under an argon atmosphere (entry 12 ). It is worth noting that $2 \mathrm{a}$ can be obtained in equally high yield when the reaction was carried out in ambient environment (entry 14). Thus, this reaction appears to have high efficiency and ease of operation, which would be useful for industrial-scale synthesis of fullerene-fused ketones.

Substrate scope of the one-step oxidation reaction. The substrate scope was further explored with some representative compounds. As shown in Table 2, this one-step oxidation reaction proceeded smoothly to afford $\mathbf{2 a}-\mathbf{d}$ in excellent yields. The optimized condition produced ketone $\mathbf{2 a}$ with an isolated yield of $94 \%$ (entry 1 ). Methyl-substituted ketone $\mathbf{2} \mathbf{b}$ was obtained in similarly high yield of $93 \%$ (entry 2 ). To investigate the electronic effect of substituents, electron-withdrawing 4-fluoro- and electron-donating 4methoxy-functionalized indano[60]fullerene substrates were synthesized. The corresponding ketones 2c and $\mathbf{2} \mathbf{d}$ were successfully isolated in excellent yields of $92 \%$ and $94 \%$, respectively (entries 3 and 4 ).

\section{Discussion}

Isotope-labelling experiments for determining the oxygen source. The successful oxidation of alkoxy indano[60]fullerene 1a under the argon atmosphere, indicating that the oxygen source was not directly from the air. Then, the oxygen source for this one-step oxidation was determined by performing the reaction in the presence of ${ }^{18} \mathrm{O}$ isotope-labelled water $\left(\mathrm{H}_{2}{ }^{18} \mathrm{O}\right)$ within a sealed tube (Fig. 2). The control experiment was performed without the addition of $\mathrm{H}_{2}{ }^{18} \mathrm{O}$ under the optimized conditions. Then, the molecular weight of the product 2a was measured by high-resolution mass spectrum (HRMS), which showed a mass-to-charge ratio $(\mathrm{m} / \mathrm{z})$ of 824.0260 corresponding to non- ${ }^{18} \mathrm{O}-$ labeled $2 \mathrm{a}$ (Fig. 2a). When the reaction was carried out in the presence of $\mathrm{H}_{2}{ }^{18} \mathrm{O}$, a peak at $\mathrm{m} / \mathrm{z} 826.0342$ was clearly observed by HRMS, indicating that the obtained ketone contained ${ }^{18} \mathrm{O}$ in its carbonyl group (Fig. 2b). Therefore, the oxygen source for this oxidation reaction is $\mathrm{H}_{2} \mathrm{O}$ rather than the methoxy group or $\mathrm{O}_{2}$ from the air. Notably, although an excess of $\mathrm{H}_{2}{ }^{18} \mathrm{O}$ was used, the mass peak of non- ${ }^{18} \mathrm{O}$ labelled ketone $2 \mathrm{a}$ can still be seen in the HRMS spectrum of the ${ }^{18}$ O-labeled ketone $2 \mathrm{a}-\left({ }^{18} 0\right)$. (See Supplementary Fig. 1, Tables 1 and 2 for details). 
Kinetic studies. Reaction kinetics of this one-step direct oxidation reaction were carried out to further understand the reaction characteristics (Fig. 3). All reactions were performed under the same conditions except varying the temperature. The concentration changes over time were monitored by highperformance liquid chromatography (HPLC) (See Supplementary Figs. 2-5, Tables 3-6 for details). The change in concentration of reactant $\mathbf{1 a}$ and product $\mathbf{2 a}$ over time clearly indicated that this oxidation reaction reached equilibrium faster and gave higher yield when the reaction temperature increased (Figs. $3 a$ and $3 b$ ). No by-products were formed during the transformation of $1 a$ to $2 a$, demonstrating that this oxidation route has high selectivity and efficiency. The consumption ratio of 1a was plotted on a logarithmic scale to determine the reaction order. The natural logarithm of the $1 \mathrm{a}$ consumption ratio exhibited a strong linear time dependence, suggesting that this oxidation reaction exhibit the first-order characteristics (Fig. 3c). The rate constant ( $k$ ) dramatically increased from $6.4 \times 10^{-4} \mathrm{~mol}^{-1} \mathrm{~L}^{-1} \mathrm{~s}^{-1}$ to $7.8 \times$ $10^{-3} \mathrm{~mol}^{-1} \mathrm{~L}^{-1} \mathrm{~s}^{-1}$ when the reaction temperature was increased from $353 \mathrm{~K}$ to $375 \mathrm{~K}$ (Table 3). Next, the activation energy $E_{\mathrm{a}}$, activation enthalpy $\Delta H^{\ddagger}$, activation entropy $\Delta S^{\ddagger}$, and activation Gibbs free energy $\Delta G^{\ddagger}$ were obtained from Arrhenius plots (In $k$ vs. $\left.1 / T\right)$ and Eyring plots $(\ln (k / T)$ vs. $1 / T)$ on the basis of following equations, respectively (Fig. 3d): $: 9,10$

$\ln k=-E_{\mathrm{a}} / \mathrm{RT}+\ln A$

$\ln (k / T)=-\Delta H^{\ddagger} / R T+\left[\ln \left(k_{\mathrm{B}} / h\right)+\Delta S^{\ddagger} / R\right]$

Here, $k$ is the rate constant, $T$ is the temperature, $R$ is the gas constant, $\ln A$ is a constant, $k_{\mathrm{B}}$ is the Boltzmann constant, $h$ is the Planck constant. The results summarized in Table 1 indicate that this onestep direct oxidation has an $E_{\mathrm{a}}$ of $120.6 \mathrm{~kJ} \mathrm{~mol}^{-1}$, with an endothermic $\Delta H^{\ddagger}$ of $116.4 \mathrm{~kJ} \mathrm{~mol}^{-1}$, a positive $\Delta S^{\ddagger}$ of $6.2 \mathrm{~J} \mathrm{~mol}^{-1} \mathrm{~K}^{-1}$.

Mechanistic studies. To gain more understandings on this one-step oxidation reaction, further investigations were carried out to understand the additional products and active intermediates. In situ proton nuclear magnetic resonance ( ${ }^{1} \mathrm{H}$ NMR) was applied to analyze the leaving form of the methyl group in 1a (Fig. 4a). As shown in Fig. 4a, ${ }^{1} \mathrm{H}$ NMR of 1a clearly depicted a methyl peak with a chemical shift $(\delta)$ at $4.252 \mathrm{ppm}$. After the reaction was fished, the in situ ${ }^{1} \mathrm{H}$ NMR of reaction mixture indicated a disappearance of methyl peak in $1 \mathrm{a}$, while a new singlet peak appeared at $\delta=2.619 \mathrm{ppm}$. Compared to the methyl peak in methanol $(\delta=2.827)$, which we hypothesized as the potential leaved form of methyl in this reaction, the reaction mixture showed substantially up-field shifted. Additionally, the reaction mixture was examined to be acidic, indicating the generation of acid during the reaction. Accordingly, we hypothesized the ${ }^{1} \mathrm{H}$ NMR signal $(\delta=2.619)$ of reaction mixture should be derived from the methyl in $\mathrm{CH}_{3} \mathrm{Br}_{1}{ }^{12}$ which was produced by the reaction between generated $\mathrm{HBr}$ and $\mathrm{MeOH}$ leaved from 1a especially reacting at high temperature. Meanwhile, when $\mathrm{CH}_{3} \mathrm{Br}$ was formed, $\mathrm{H}_{2} \mathrm{O}$ was simultaneously generated, which could then serve again as an oxygen source for this oxidation. Also, this result explained 
why non $-{ }^{18} \mathrm{O}$ labelled $2 \mathrm{a}$ was still detected even when we used a large excess of $\mathrm{H}_{2}{ }^{18} \mathrm{O}$. Therefore, the methyl group in 1a leaved in a methanol form, which further suggests that this oxidation reaction should involve a hemiketal intermediate. Also, the slightly positive $\Delta S^{\ddagger}$ of this reaction reasonably explained the increased disorder because of the additional products of $\mathrm{MeOH}$ and $\mathrm{HBr}$. Besides the analysis of additional products that generated during the reaction, further experiments were performed to confirm which active intermediate that mediated this one-step oxidation. Then, the radical scavenger 2,2,6,6tertramethyl-1-piperidinyloxyl (TEMPO) was applied to confirm the generation of $\mathrm{C}_{60}{ }^{\cdot+}$ intermediate from the single electron transfer between fullerene and $\mathrm{CuBr}_{2}$ (Fig. $4 \mathrm{~b}$ ). When the reaction was run in the presence of 4.0 equiv. of TEMPO, the yield of 2 a was dramatically decreased from $95 \%$ to $8 \%$. A further increase in amount of TEMPO to 10.0 equiv. stopped the reaction, suggesting that the electron transfer process was completely suppressed. Therefore, the one-step direct oxidation of alkoxy is initiated by electron transfer from $\mathrm{C}_{60}$ to $\mathrm{CuBr}_{2}$, and $\mathrm{C}_{60}{ }^{\circ+}$ plays a key role in the following oxidation steps.

Our mechanistic insights regarding to the $\mathrm{C}_{60}{ }^{\circ+}$ intermediate mediated one-step oxidation are provided in Fig. 5. Based on the above experimental results and our previous research, ${ }^{7}$ we considered that the oxidation of fullerene to $\mathrm{C}_{60}{ }^{\cdot+}$ through single electron transfer in the presence of copper bromide demonstrate a critical role in this reaction. As depicted in Fig. 5 , in this one-step oxidation, we hypothesized that the fullerene pendant in $1 \mathrm{a}$ is initially oxidized by $\mathrm{CuBr}_{2}$ via single-electron transfer, producing the key active specie, indano[60]fullerenyl radical cation I. Owing to the electron deficiency of $\mathrm{C}_{60}{ }^{\circ+}$, the neighbouring $\mathrm{C}-\mathrm{H}$ bond is then cleaved to generate neutral radical II with the release of one proton, which then spontaneously reacting with the isolated bromide anion to form $\mathrm{HBr}$. Next, $\mathrm{CuBr}_{2}$ further oxidizes II to generate corresponding cation III, which undergoes nucleophilic addition by $\mathrm{H}_{2} \mathrm{O}$, producing hemiketal intermediate IV. Finally, [60]fullerene-fused ketone $\mathbf{2} \mathbf{a}$ is produced through the loss of methanol and deprotonation. Meanwhile, the methanol produced can react with $\mathrm{HBr}$ to generate $\mathrm{CH}_{3} \mathrm{Br}$ and $\mathrm{H}_{2} \mathrm{O}$, which then quickly reacts with benzyl cation III (See Supplementary Fig. 6 for details). Therefore, fullerene pendant can facilitate the one-step direct oxidation of the alkoxy group to ketone by serving as an electron pool.

Computation studies. To provide further support for the proposed mechanism, density functional theory (DFT) calculations were performed to understand the key species and reaction barriers (Fig. 6, See Supplementary Table 7 for details). The DFT results indicated that the rate-determining step is proton transfer from $\mathrm{H}_{2} \mathrm{O}$ to the methoxy group, which had computed potential energy barrier of $124.5 \mathrm{~kJ} \mathrm{~mol}^{-1}$, in fair agreement with the experiment value. It should be noted that $\mathrm{Br}^{-}$efficiently accelerated this proton transfer, as shown by DFT calculations in the absence of $\mathrm{Br}^{-}$(See Supplementary Fig. 7 and Table 9 for details). In addition, the calculations showed facile oxidation of 1a by copper (II) and relatively easy deprotonation of I to form the benzyl cation III and HBr, with an energy barrier on the order of $38.6 \mathrm{~kJ} \mathrm{~mol}^{-}$ ${ }^{1}$ (See Supplementary Fig. 8 for details). Therefore, $\mathrm{CuBr}_{2}$ plays two roles in this one-step oxidation 
reaction: a) oxidation of fullerene via electron transfer with assistance of bromide anion; b) proton transfer for formation of the hemiketal through the formation of $\mathrm{Br}^{-}$.

Performance of evaporable fullerene-fused ketone. So far, fullerene derivatives have been demonstrated as versatile and high-performance electron-transport materials in perovskite solar cells, ${ }^{13,14}$ but the highperformance fullerene electron-transport materials have never been achieved using vacuum-deposition process. ${ }^{15-17}$ Accordingly, both the indano[60]fullerene 1a and the produced fullerene-fused ketone $\mathbf{2 a}$ were further processed through the vacuum-deposition process to fabricate the electron-transport layer. HPLC analyses of vacuum-deposited 1a-film indicated that 1a is instable in the vacuum-deposition process (Fig. 7a). To our delight, we observed that no thermally decomposed components were detected when vacuum-depositing $\mathbf{2 a}$, which indicated fullerene-fused ketone has stronger stability (Fig. $7 \mathrm{~b}$ ). Further thermogravimetric analyses (TGA) manifested that 2a show high thermal stability with an initial decomposing temperature at $409.5^{\circ} \mathrm{C}$, which is much thermally stable than that of $1 \mathrm{a}$ or $\mathrm{PC}_{61} \mathrm{BM}$ (See Supplementary Fig. 9 for details). Transmission electron microscopy (TEM) was carried to compare the morphology of spin-coated and vacuum-deposited 2a-films, respectively. Fig. 7c indicated that the spincoated 2a-film show obvious pinholes with substantial crystalline found in the selected area electron diffraction (See Supplementary Fig. 10a for details). In stark contrast, the vacuum-deposited 2a-film exhibits a highly uniform and amorphous morphology, which benefits the high electron-transport performance (Fig. 7d and See Supplementary Fig. 10b for details). ${ }^{6}$ To evaluate the charge carrier mobility of fullerene-fused ketone $\mathbf{2 a}$, space-charge-limited current (SCLC) measurements was applied to compare the trap-filling limit voltage $\left(V_{\mathrm{TFL}}\right)$ and trap density $\left(n_{\mathrm{t}}\right)$ of spin-coated and vacuum-deposited $\mathbf{2 a}$ films, respectively (Figs. 7e \& 7f). In well accordance with TEM observations, the spin-coated 2a-film showed more defects with higher $V_{\mathrm{TFL}}(1.49 \mathrm{~V})$ and $n_{\mathrm{t}}\left(1.4 \times 10^{18} \mathrm{~cm}^{-3}\right)$, compared with $V_{\mathrm{TFL}}(1.01 \mathrm{~V})$ and $n_{\mathrm{t}}\left(9.3 \times 10^{17} \mathrm{~cm}^{-3}\right)$ of the vacuum-deposited 2a-film. Moreover, additional SCLC measurements further compared vacuum-deposited $\mathrm{C}_{60^{-}}$and $2 \mathrm{a}$-films (Figs. $7 \mathrm{~g}$ and $7 \mathrm{~h}$ ). The $2 \mathrm{a}$-film exhibited an equally high electron mobility $\left(2.16 \times 10^{-6} \mathrm{~cm}^{2} \mathrm{~V}^{-1} \mathrm{~s}^{-1}\right)$ compared with $\mathrm{C}_{60}-$ film $\left(2.33 \times 10^{-6} \mathrm{~cm}^{2} \mathrm{~V}^{-1} \mathrm{~s}^{-1}\right)$, which suggesting that fullerene-fused ketone can be applied as an efficient electron-transport layer to replace the pristine [60]fullerene in perovskite solar cells.

In summary, here we report a facile $\mathrm{CuBr}_{2}$-promoted one-step direct oxidation of alkoxy to ketone with the aid of an oxidizable fullerene pendant. The mechanistic investigation demonstrates in situ generated fullerenyl radical cation $\left(\mathrm{C}_{60}{ }^{-+}\right)$behaves as an electron pool to facilitate the one-step direct oxidation: a) initiating oxidation via electron transfer from $\mathrm{C}_{60}$ to $\mathrm{CuBr}_{2}$ to form $\mathrm{C}_{60}{ }^{\cdot+}$ and b) activating cleavage of the neighbouring $\mathrm{C}-\mathrm{H}$ bond by withdrawing electrons from the bond and subsequently affording the key hemiketal intermediate. Moreover, we found that produced fullerene-fused ketone can form the highquality electron-transport film using the vacuum-deposited process. Therefore, this reaction will not only provide a useful method in fundamental organic chemistry regarding the direct oxidation of alkoxy to ketone and in fullerene cation chemistry, but also provide an evaporable fullerene material for highperformance electron-transport material in perovskite solar cells. 


\section{Declarations}

\section{Acknowledgements}

We gratefully acknowledge funding from the Research and Education Consortium for Innovation of Advanced Integrated Science by the Japan Science and Technology Agency (JST) and Japan Society for the Promotion of Science (JSPS) KAKENHI Grant Numbers JP15H05760, JP17H06609, 20 J13124.

\section{Author contributions}

H.-S. L. and Yue. M. are contributed equally to this work. H.-S. L. and Yut. M. conceived idea and wrote the manuscript. R. X. and S. M. conducted TEM observations. S. M. and I. J. conducted DFT calculation.

\section{Competing interests}

The authors declare no competing interests.

\section{References}

1. Carey, F. A., Giuliano, R. M. Organic Chemistry, (McGraw-Hill Education, New York, 2016).

2. Firouzabadi, H., Pourali, A. R. Dinitrogen tetroxide-impregnated charcoal $\left(\mathrm{N}_{2} \mathrm{O}_{4} /\right.$ charcoal): selective nitrosation of amines, amide, ureas, and thiols. Comm. 35, 1527-1533 (2005).

3. Gilissen, P. J., Blanco-Ania, D., Rutjes, F. P. J. T. Oxidation of secondary methyl ethers to ketones. Org. Chem. 82, 6671-6679 (2017).

4. Fagan, P. J., Calabrese, J. C., Malone, B. The chemical nature of buckminsterfullerene $\left(\mathrm{C}_{60}\right)$ and the characterization of a platinum derivative. Science 252, 1160-1161 (1991).

5. Echegoyen, L., Echegoyen, L. E. Electrochemistry of fullerenes and their derivatives. Chem. Res. 31, 593-601 (1998).

6. Hashiguchi, M., Obata, N., Maruyama, M., Yeo, K. S., Ueno, T., Ikebe, T., Takahashi, I., Matsuo, Y. $\mathrm{FeCl}_{3}-$ Mediated synthesis of fullerenyl esters as low-LUMO acceptors for organic photovoltaic devices. Lett. 14, 3276-3279 (2012).

7. Lin, H.-S., Matsuo, Y. Functionalization of [60]fullerene through fullerene cation intermediates. Comm. 54, 11244-11259 (2018).

8. Lin, H.-S., Jeon, I., Chen, Y., Yang, X.-Y., Nakagawa, T., Maruyama, S., Manzhos, S., Matsuo, Y. Highly selective and scalable fullerene-cation-mediated synthesis accessing cyclo[60]fullerenes with fivemembered carbon ring and their application to perovskite solar cells. Mater. 31, 8432-8439 (2019).

9. Arrhenius, S. A. Über die dissociationswärme und den einfluss der temperatur auf den dissociationsgrad der elektrolyte. Phys. Chem. 4, 96-116 (1889).

10. Eyring, H. J. The activated complex in chemical reactions. Chem. Phys. 3, 107-115 (1935). 
11. Ueno, H., Kawakami, H., Nakagawa, K., Okada, H., Ikuma, N., Aoyagi, S., Kokubo, K., Matsuo, Y., Oshima, T. Kinetic study of the diels-alder reaction of $\mathrm{Li}^{+} @ \mathrm{C}_{60}$ with cyclohexadine: greatly increased reaction rate by encapsulated $\mathrm{Li}^{+}$. Am. Chem. Soc. 136, 11162-11167 (2014).

12. Lacey, M. J., Macdonald, C. G., Pross, A., Shannon, J. S., Sternhell, S. Geminal interproton coupling constants in some methyl derivatives. J. Chem. 23, 1421-1429 (1970).

13. Li, Y., Zhao, Y., Chen, Q., Yang, Y. M., Liu, Y., Hong, Z., Liu, Z., Hsieh, Y.-T., Meng, L., Li, Y., Yang, Y. Multifunctional fullerene derivative for interface engineering in perovskite solar cells. Am. Chem. Soc. 137, 15540-15547 (2015).

14. Liu, K., Chen, S., Wu, J., Zhang, H., Qin, M., Lu, X., Tu, Y., Meng, Q., Zhan, X. Fullerene derivative anchored $\mathrm{SnO}_{2}$ for high-performance perovskite solar cells. Energy Environ. Sci. 11, 3463-3471 (2018).

15. Lin, H.-S., Jeon, I., Xiang, R., Seo, S., Lee, J.-W., Li, C.; Pal, A., Manzhos, S., Goorsky, M. S., Yang, Y., Maruyama, S., Matsuo, Y. Achieving high efficiency in solution-processed perovskite solar cells using $\mathrm{C}_{60} / \mathrm{C}_{70}$ mixed fullerenes. ACS Appl. Mater. Interfaces 10, 39590-39598 (2018).

16. Collavini, S., Kosta, I., Völker, S. F., Cabanero, G., Grande, H. J., Tena-Zaera, R., Delgado, J. L. Effıcient regular perovskite solar cells based on pristine [70]fullerene as electron-selective contact. ChemSusChem 9, 1263-1270 (2016).

17. Lee, K.-M., Chen, C.-C., Chen, L.-C., Chang, S. H., Chen, K.-S., Yeh, S.-C., Chen, C.-T., Wu, C.-G. Thickness effects of thermally evaporated $\mathrm{C}_{60}$ thin films on regular-type $\mathrm{CH}_{3} \mathrm{NH}_{3} \mathrm{Pbl}_{3}$ based solar cells. Energy Mater. Sol. Cells 164, 13-18 (2017).

\section{Tables}


Table 1 Optimization of reaction conditions ${ }^{a}$
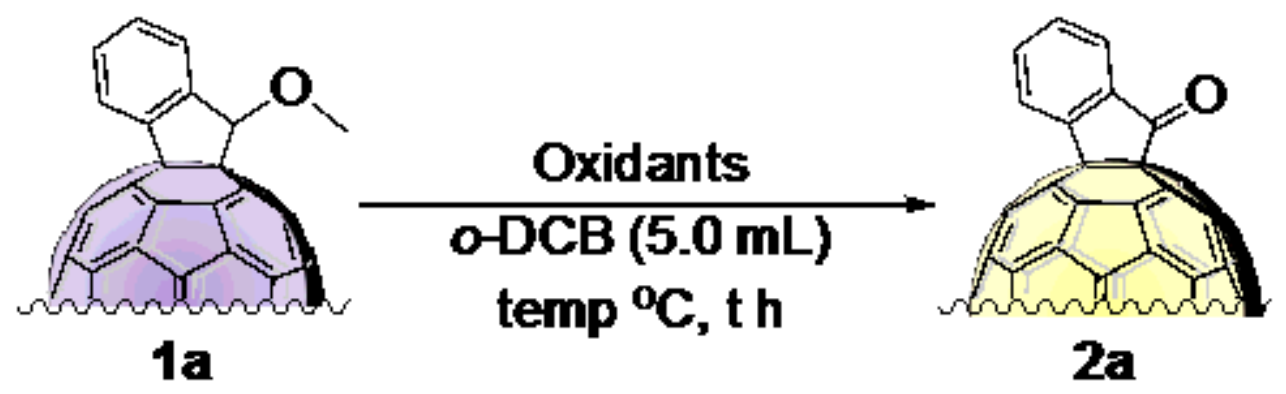

\begin{tabular}{cccccc}
\hline Entry & Oxidants & Equiv. & Temp (oC) & Tme (h) & Yreld (\%) $^{\mathbf{b}}$ \\
\hline 1 & - & - & 100 & 4.0 & N.R.c \\
2 & $\mathrm{~K}_{2} \mathrm{~S}_{2} \mathrm{O}_{8}$ & 2.0 & 100 & 4.0 & N.R. \\
3 & $\mathrm{Ag}_{2} \mathrm{O}$ & 2.0 & 100 & 4.0 & N.R. \\
4 & $\mathrm{CuO}$ & 2.0 & 100 & 4.0 & N.R. \\
5 & $\mathrm{CuBr}_{2}$ & 2.0 & 100 & 4.0 & 43 \\
6 & $\mathrm{CuBr}_{2}$ & 4.0 & 100 & 4.0 & 95 \\
7 & $\mathrm{CuBr}_{2}$ & 6.0 & 100 & 4.0 & 92 \\
8 & $\mathrm{CuBr}_{2}$ & 4.0 & 100 & 20 & 94 \\
9 & $\mathrm{CuBr}_{2}$ & 4.0 & 90 & 20 & 88 \\
10 & $\mathrm{CuBr}_{2}$ & 4.0 & 80 & 20 & 57 \\
11 & $\mathrm{CuBr}_{2}$ & 4.0 & 70 & 20 & N.R. \\
12 & $\mathrm{CuBr}_{2}$ & 4.0 & 100 & 1.5 & 94 \\
13 & $\mathrm{CuBr}_{2}$ & 4.0 & 100 & 1.0 & 89 \\
14 & $\mathrm{CuBr}_{2}$ & 4.0 & 100 & 1.5 & 92 \\
\hline
\end{tabular}

anless otherwise specified, all reactions were perfommed with $0.03 \mathrm{mmol}$ of $1 \mathrm{a}$ in $10.0 \mathrm{~mL}$ of o-DCB under an agon atrmosphere. environment 


\section{Table 2 Scope of the reaction}
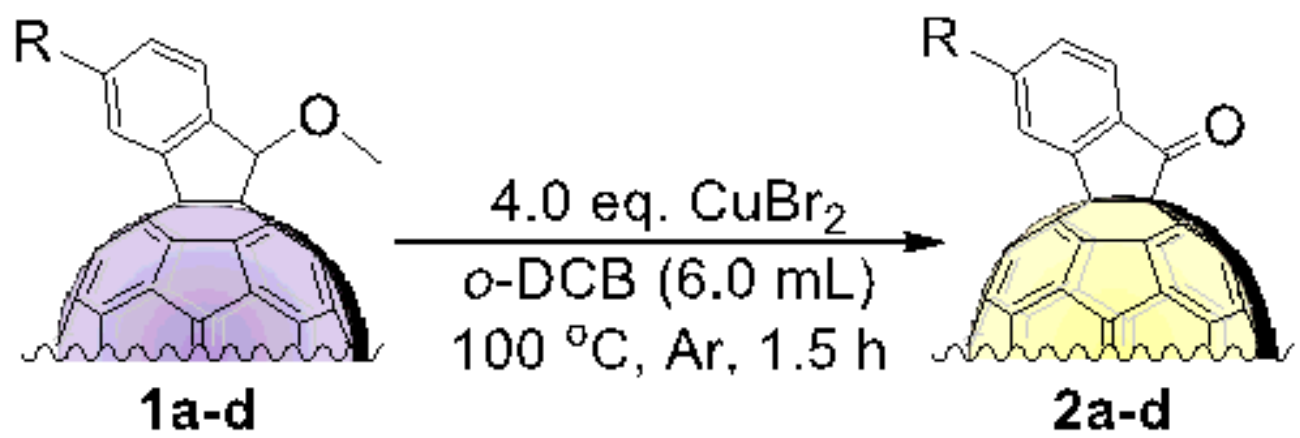

\begin{tabular}{|c|c|c|c|c|c|}
\hline Entry & Products & Yield (\%) & Entry & Products & Yield (\%) \\
\hline
\end{tabular}

1

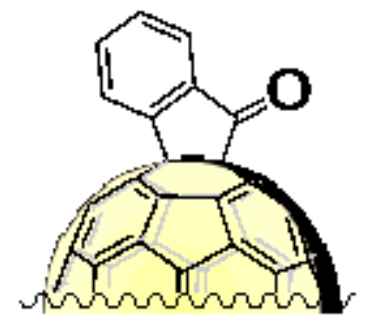

$2 a$

2

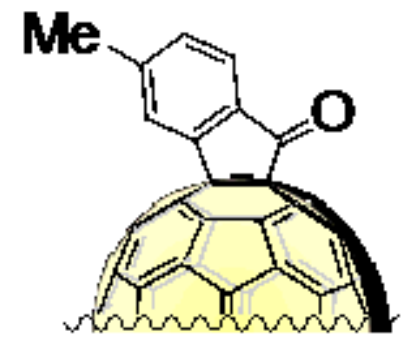

Zb
94

93

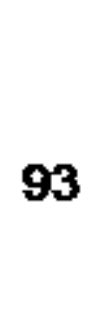

3

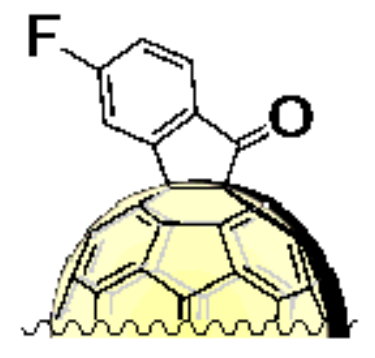

2c

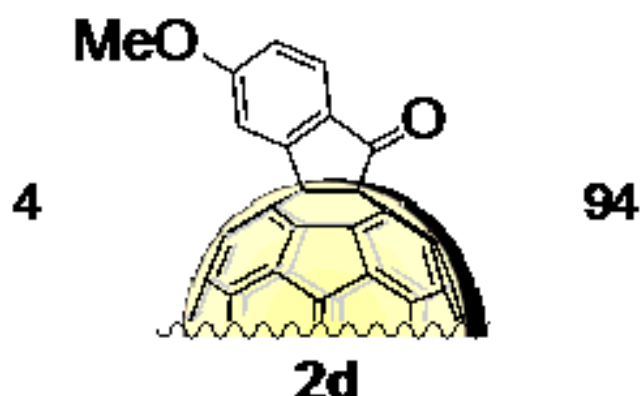

Reaction conditions: al the reactions were performed with $0.02 \mathrm{mmol}$ of $1 \mathrm{a}-\mathrm{d}, 0.08 \mathrm{mmol}$ of $\mathrm{CuBr}_{2} \mathrm{in} 6.0 \mathrm{~mL}$ of $o-\mathrm{DCB}$ solution at $100^{\circ} \mathrm{C}$ for $1.5 \mathrm{~h}$ under an agon atmosphere.

Table 3 Kinetic parameters of the one-step oxidation reaction ${ }^{a}$

\begin{tabular}{|llllll|}
\hline $\begin{array}{l}\text { Temp. } \\
(\mathrm{K})\end{array}$ & $\begin{array}{l}\text { Rate constant } \\
\left(\mathrm{mol}^{-1} \mathrm{~L}^{-1} \mathrm{~s}^{-1}\right)\end{array}$ & $\begin{array}{l}E_{\mathrm{a}} \\
\left(\mathrm{kJ} \mathrm{mol}^{-1}\right)\end{array}$ & $\begin{array}{l}\Delta H^{\ddagger} \\
\left(\mathrm{kJ} \mathrm{mol}^{-1}\right)\end{array}$ & $\begin{array}{l}\Delta S^{\ddagger} \\
\left(\mathrm{J} \mathrm{mol}^{-1} \mathrm{~K}^{-1}\right)\end{array}$ & $\begin{array}{l}\Delta G^{\ddagger} \\
\left(\mathrm{kJ} \mathrm{mol}^{-1}\right)\end{array}$ \\
353 & $\begin{array}{l}6.4 \times 10^{-4} \\
360\end{array}$ & 120.6 & 116.4 & 6.2 & 114.1 \\
368 & $\begin{array}{l}1.5 \times 10^{-3} \\
368 \times 10^{-3}\end{array}$ & & & & \\
375 & $7.8 \times 10^{-3}$ & & & & \\
\hline
\end{tabular}


activation free energy $\Delta G^{\ddagger}$ was estimated from $\Delta H^{\ddagger}, \Delta S^{\ddagger}$ and temperature at $375 \mathrm{~K}$ according to the equation $\Delta G^{\ddagger}=\Delta H^{\ddagger}-\mathrm{T} \Delta S^{\ddagger} .{ }^{11}$

\section{Figures}
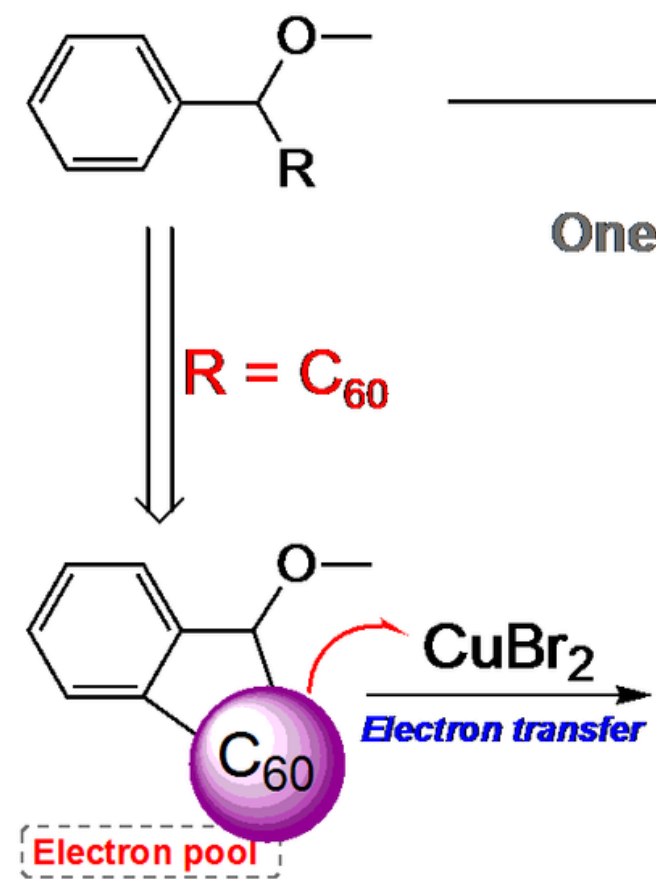

$\mathrm{CuBr}_{2}$

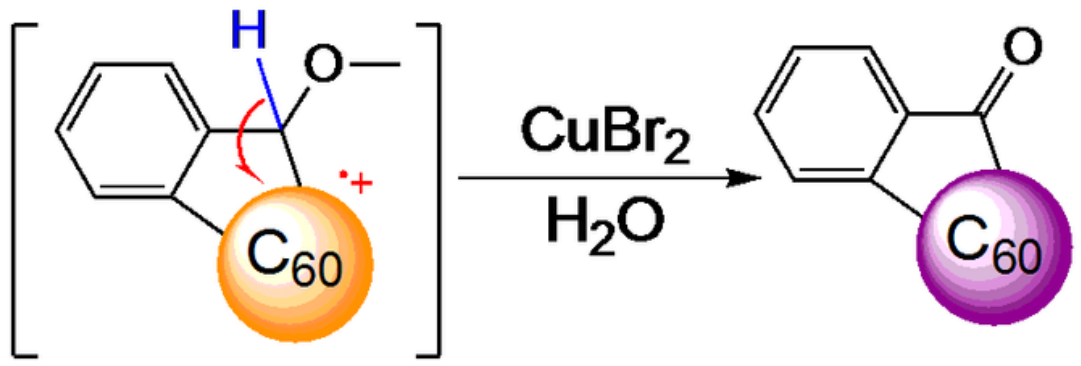

Fullerenyl radical cation

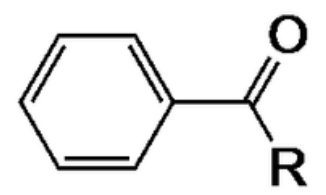

Fullerene-fused ketone

Figure 1

Working concept. One-step direct oxidation of alkoxy groups to ketones with the fullerene as redox pendant. 
a) Absence of $\mathrm{H}_{2}{ }^{18} \mathrm{O}$

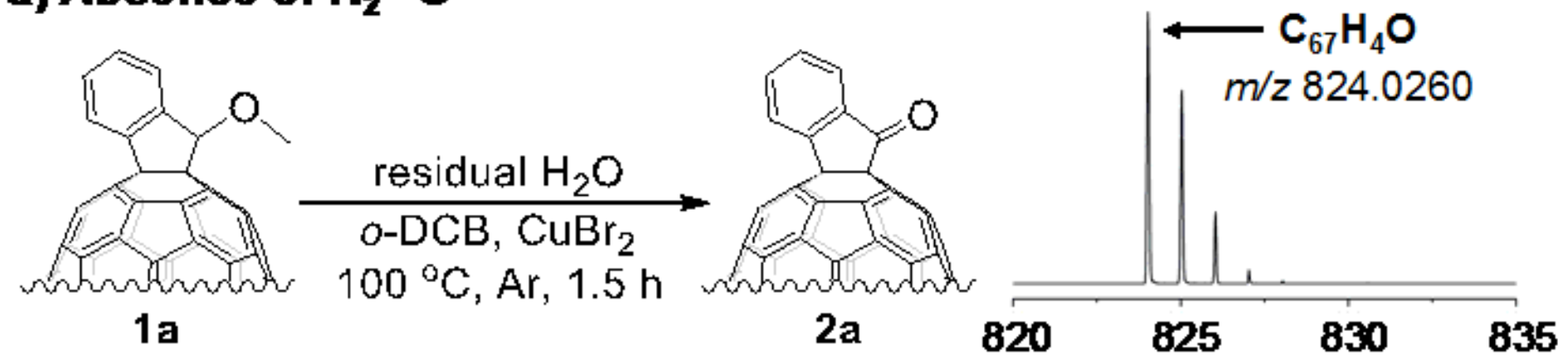

\section{b) 20.0 equiv. of $\mathrm{H}_{2}{ }^{18} \mathrm{O}$}

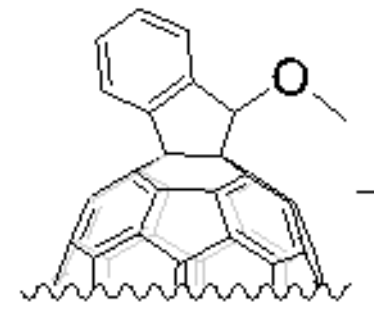

1a

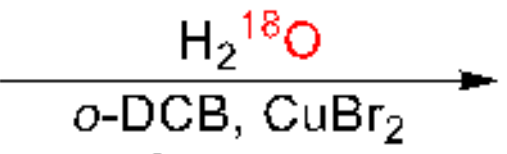
$100^{\circ} \mathrm{C}, \mathrm{Ar}, 1.5 \mathrm{~h}$

820

825 835

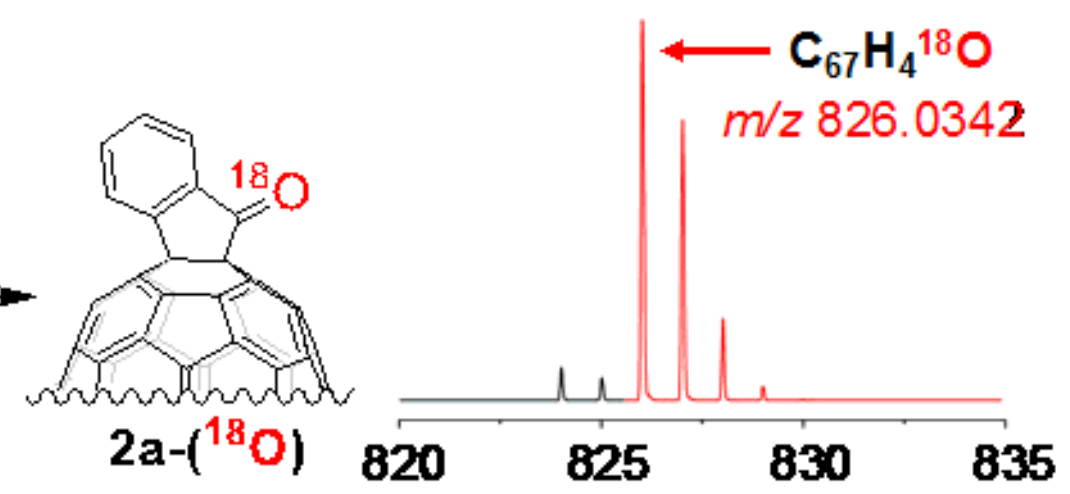

Figure 2

180 isotope-labelling experiments. Reaction conditions: $1 \mathrm{a}(3.0 \mathrm{mg}, 3.6 \mu \mathrm{mol}), \mathrm{CuBr} 2$ (4.0 equiv.), o-DCB $\left(3.0 \mathrm{~mL}\right.$ ) at $100{ }^{\circ} \mathrm{C}$ for $1.5 \mathrm{~h}$ in a sealed tube. a) Absence of H2180. b) 20.0 equiv. $\mathrm{H} 2180$. 

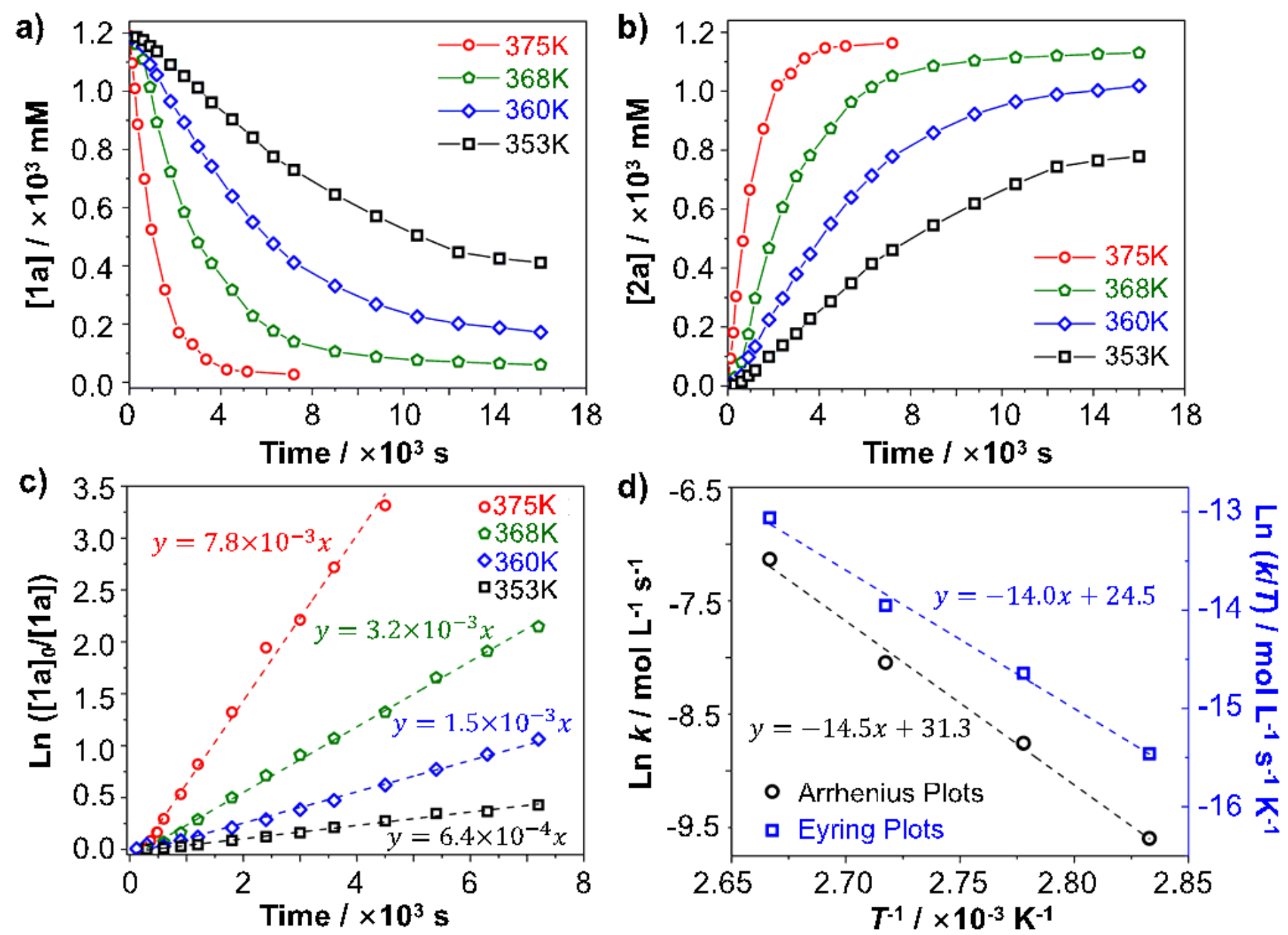

Figure 3

Reaction kinetics. Reaction conditions: 1a (3.0 mg, $3.6 \mu \mathrm{mol})$, CuBr2 (4.0 equiv.), o-DCB (3.0 mL). a) Concentration of 1 a over time at different temperatures. b) Concentration of 2a over time at different temperatures. c) Plots of $\ln ([1 \mathrm{a}] 0 /[1 \mathrm{a}])$ over time at different temperatures, where [1a]0 and [1a] are the initial and remaining concentrations of 1 a, respectively. d) Arrhenius plot (black) and Eyring plot (blue) for this one-step oxidation reaction. 

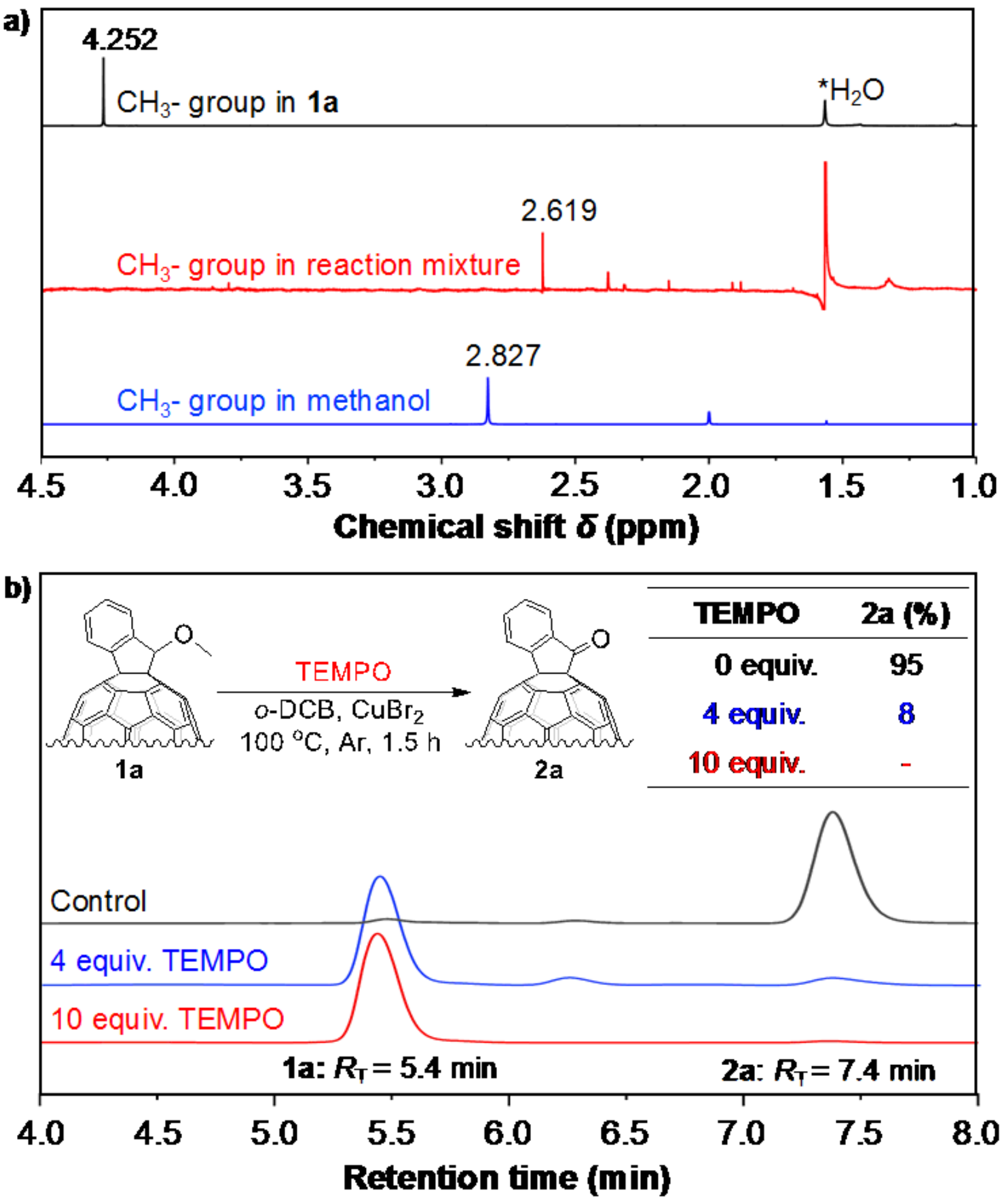

Figure 4

Mechanistic studies. a) $1 \mathrm{H}$ NMR with the $\mathrm{H} 2 \mathrm{O}$ as internal reference located at up-field for identifying the methyl structure of $1 \mathrm{a}$ (black), reaction mixture (red), and methanol (blue). b) Experiments in the presence of different amount of TEMPO as radical scavenger. 

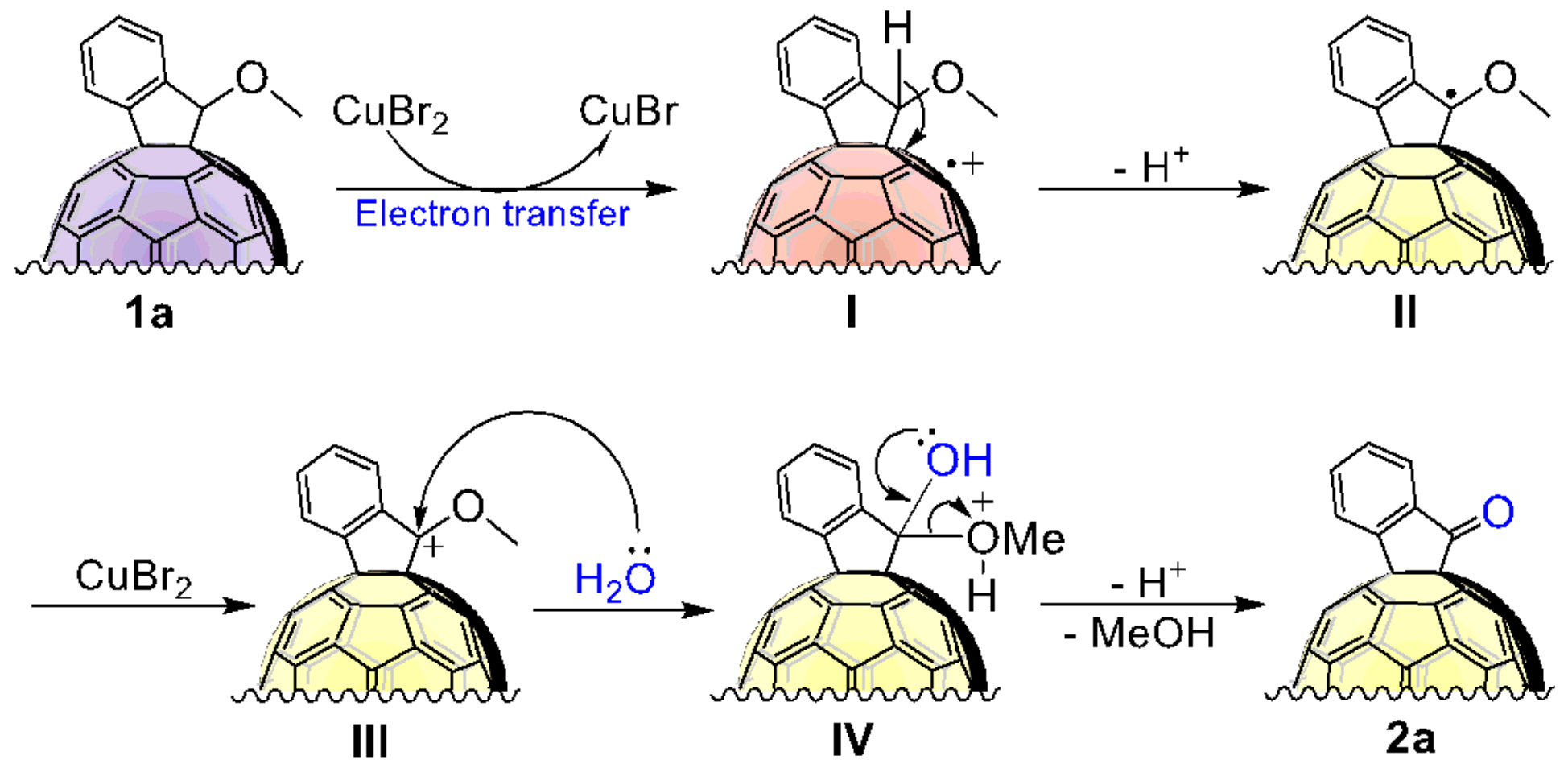

Figure 5

Proposed mechanism. Plausible mechanism for $\mathrm{CuBr2-promoted} \mathrm{one-step} \mathrm{direct} \mathrm{oxidation} \mathrm{of} \mathrm{alkoxy}$ group to ketone. 


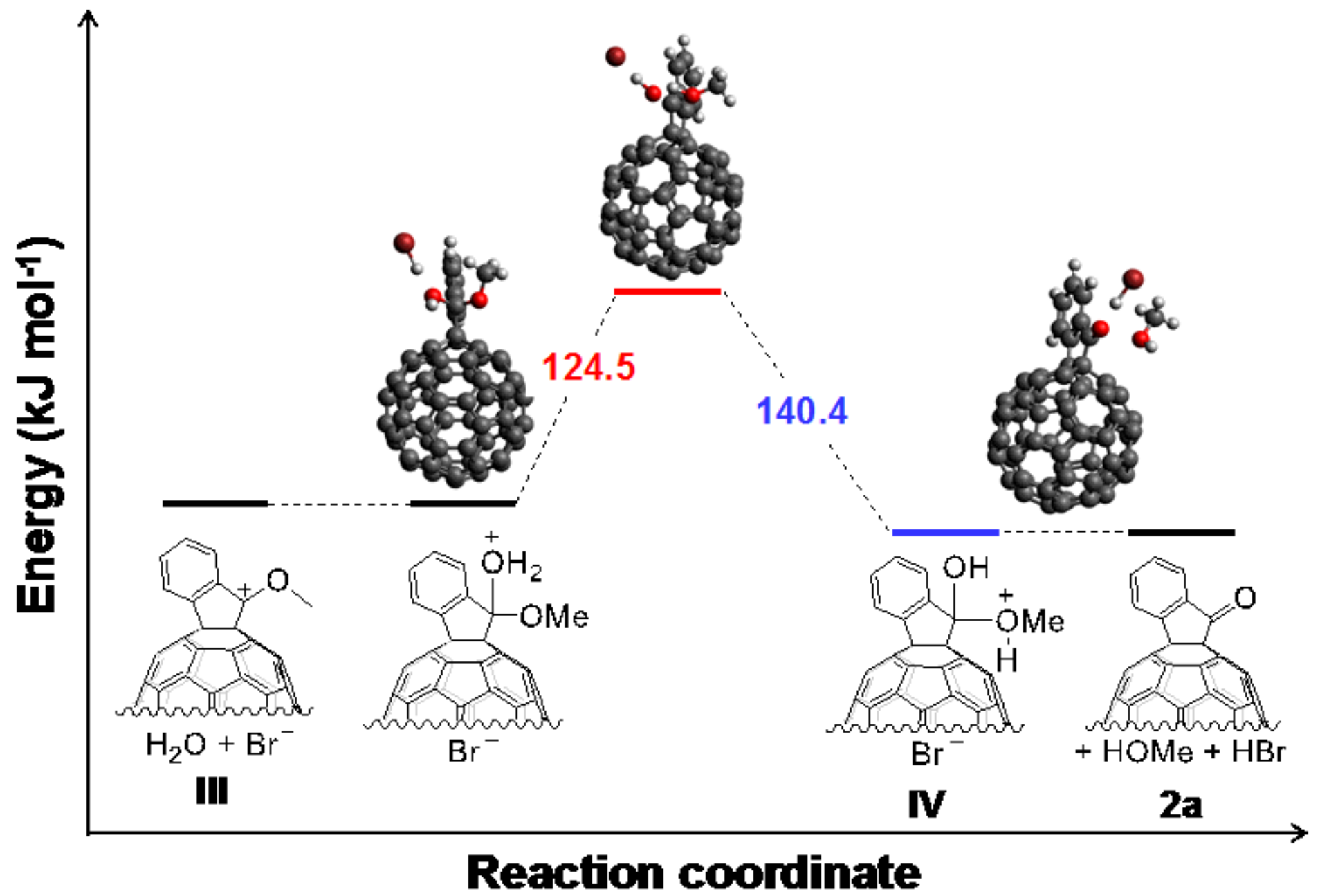

Figure 6

Computation studies. DFT calculation for the key step from intermediate III to $2 \mathrm{a}$ in the presence of $\mathrm{Br}-$. 

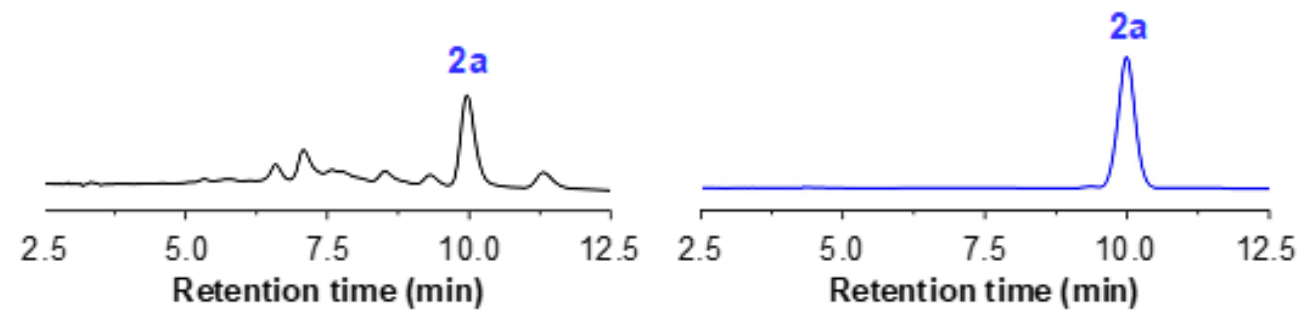

c)
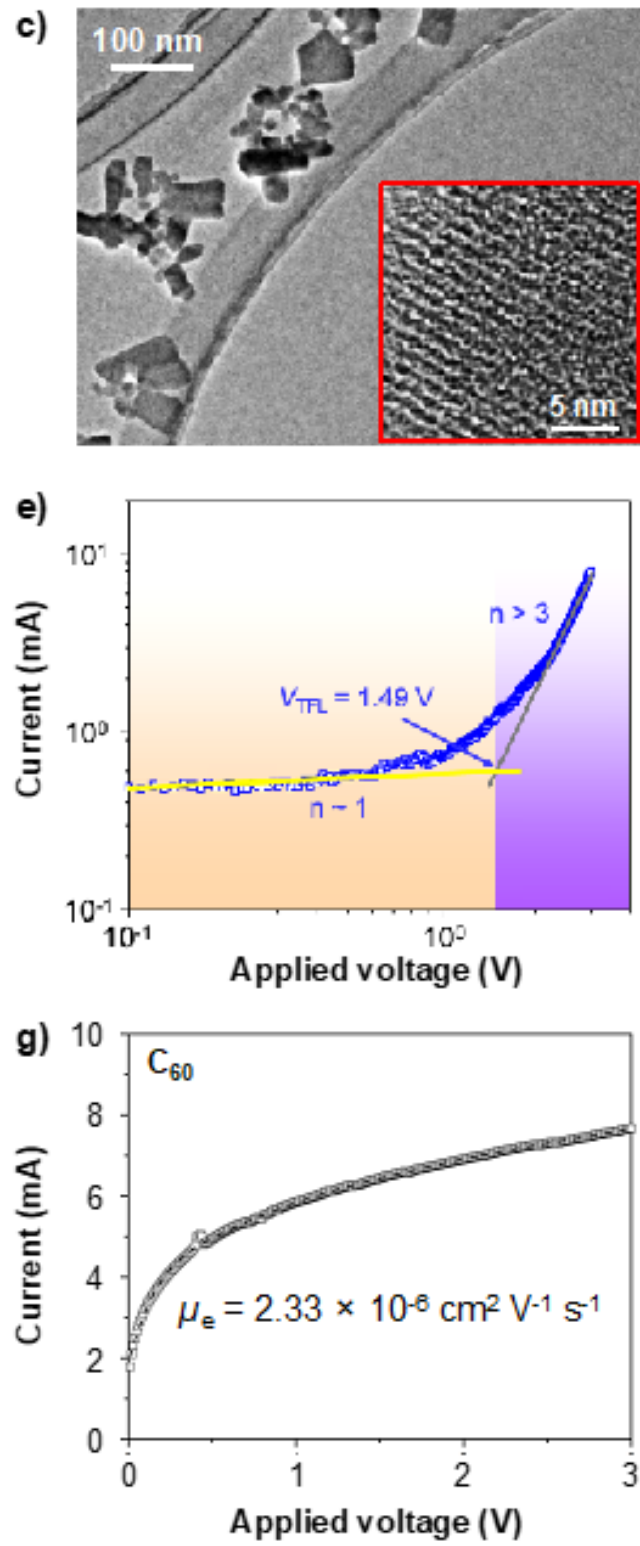

d)
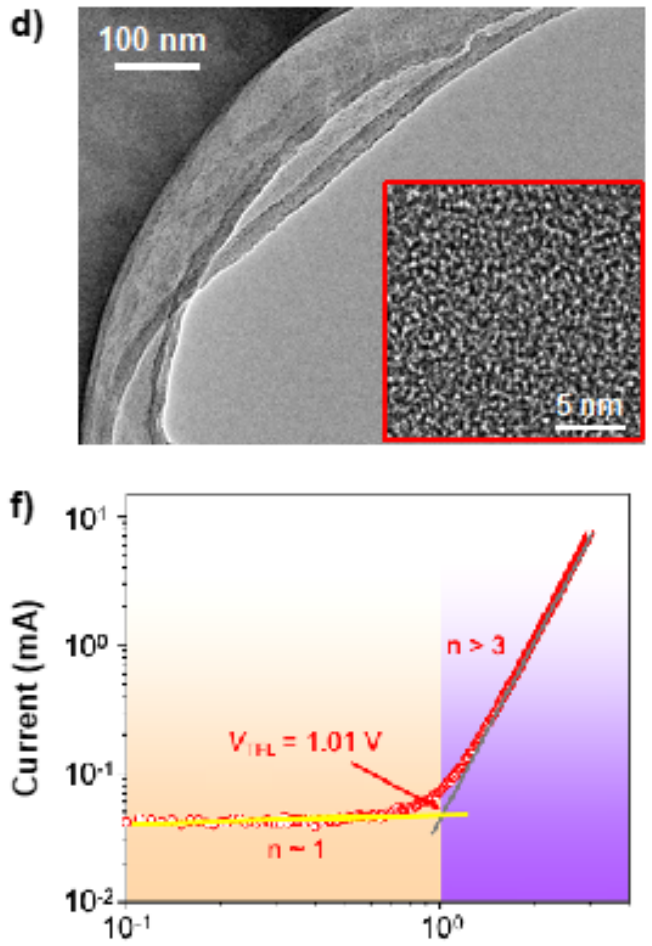

Applied voltage (V)

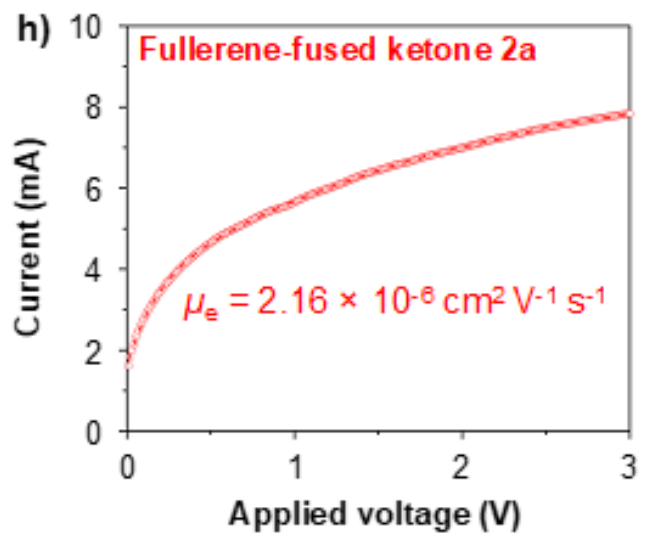

\section{Figure 7}

Properties of evaporable fullerene-fused ketone material. HPLC analyses of a) vacuum-deposited indano[60]fullerene 1a-film. b) Vacuum-deposited [60]fullerene-fused ketone 2a-film. TEM observations of c) spin-coated 2a-film and d) vacuum-deposited 2a-film with the magnification as an inset. Trap density measurement of e) spin-coated 2a-film and f) vacuum-deposited 2a-film. The SCLC based electron mobility measurement of g) vacuum-deposited C60-film and h) vacuum-deposited 2a-film. 


\section{Supplementary Files}

This is a list of supplementary files associated with this preprint. Click to download.

- SI.CC.pdf 